\title{
Our New President
}

The number of ballot forms issued was 4,790 of which 2,064 (43 per cent) were returned (of these, 55 were considered invalid). Professor Rawnsley received 953 (47 per cent) of the 2,009 votes cast.]

Professor Kenneth Rawnsley was installed as our President at the Annual Meeting of the College held in London on $9 \mathrm{July,}$ 1981. He has played a major part in the formation and development of the College since its inception ten years ago. In four hundred words the biographical (sic) note which he provided for us to accompany the ballot papers contains an impressive list of his achievements in psychiatric teaching and research. It also indicates his considerable contribution to medical affairs in Wales and far beyond.

Rawnsley qualified in Manchester in 1948 and trained in psychiatry in Manchester and at the Maudsley. He became a member of the MRC Social Psychiatry Unit at the Institute of Psychiatry, and in 1961, at the early age of 37, was appointed Professor and Head of the Department of Psychological Medicine in the Welsh National School of Medicine at Cardiff. Here he continued his research in social psychiatry with work on the epidemiology of mental illness in Wales, and subsequently he pursued this interest in other countries-most recently among the people of Tristan da Cunha.

He has served his Medical School as its Vice-Provost and has been a member of many major national committees, including the Merrison Committee of Inquiry into the Regulation of the Medical Profession. Stemming from this work, and indeed preceding it, has been his concern for the sick doctor. He is Chairman of the College's Special Committee on Sick Doctors, and was responsible for establishing a con- fidential system of helping such doctors in conjunction with the Association of Anaesthetists. He hopes to extend this type of service for other specialists.

He joined the RMPA in 1951, served on its Council, and when the College was formed in 1971 became our first Dean. The job involved setting up the Approval panels and visits and supervising the introduction of the Membership Examination. His experience with the Approval exercise has been invaluable to him as Chairman of the Joint Committee on Higher Psychiatric Training. Having completed five years as Dean he became Vice-President for the years 1978 and 1979.

These are merely a few of Rawnsley's contributions to the College so far, and we can look forward to many new developments. He has indicated that he hopes to consolidate the work already started rather than make any immediate changes, and to move towards a further raising of training standards through the activities of the Central Approval Panel. He also wishes to encourage a wide debate within the College on the form and timing of the Membership Examination.

He believes passionately in the importance of the medical contribution to psychiatric care, and under his leadership we can expect further definition of the psychiatrist's role with respect to the other professions working in the mental health service. He plans to continue the tradition established by his predecessors by visiting the Divisions of the College and getting to know as many members as possible. We are sure that he will have a successful Presidency and we hope that he and his wife, Dr Elinor Kapp, also a psychiatrist, will find their period of office enjoyable. We wish them well.

\section{Tenth Anniversary Reception}

The Tenth Anniversary of the College was celebrated with a Reception at the College on Tuesday 16 June, 1981 in the presence of Her Royal Highness Princess Alexandra and the Honourable Angus Ogilvy.

Members of Council, Court of Electors, representatives of Sections and Divisions and some of those who helped to make the College a reality were invited, as well as the College staff (who were generally deployed to ensure the smooth running of the evening).
Elegant flower arrangements began to appear at strategic points around the College on Monday, and fascinating old photographs of past Presidents and officers adorned the walls. By five o'clock on Tuesday evening everything was ready.

On arrival, Princess Alexandra was greeted by Sir Desmond Pond and introduced to the Honorary Officers and some members of the staff in the entrance hall. She talked to everyone and asked about the College and its adminis- 
tration. An enthusiastic inquiry by $\mathrm{Mr}$ Ogilvy into the activities of the Research Office was met with an apologetic "sorry, that's confidential".

Princess Alexandra, accompanied by Sir Desmond Pond and $\mathrm{Dr} \mathrm{T}$. H. Bewley, and Mr Ogilvy, accompanied by $\mathrm{Dr}$ P. H. Connell and Professor Timbury, closely followed by Lady Mary Fitzalan-Howard, Lady-in-Waiting and Miss Natalie Cobbing, College Secretary, then proceeded to the President's room, where more guests and members of staff were assembled. From here they progressed to the Council Room and adjoining Library, finally arriving in the Warren Suite.

It was particularly gratifying to see among those gathered some of our older Fellows who played such important parts in the transformation of the Royal Medico-Psychological
Association to the Royal College of Psychiatrists. As well as members of the old "Petition Committee", Dr John Howells, Dr J.T. Hutchinson and Dr William Sargant, we were delighted to see past Presidents, Dr L. C. Cook (1958), Dr Martin Cuthbert (1969-71) and Sir Martin Roth (1971-75). Dr Wilfrid Warren, our past Treasurer, was among the first to greet the Royal guest in the newly named Warren Suite, our interchangeable basement lecture theatres, committee rooms and dining area.

Before their departure at $7.30 \mathrm{pm}$, Princess Alexandra and Mr Ogilvy signed the Visitors' Book. Members were then able to wander round the College, meeting old friends and admiring the new decorations in the entrance hall, main staircase, Council Room as well as the Warren Suite.

\title{
The Role of MIND in Relation to Psychiatry*
}

\author{
TONY SMYTHE, National Director, MIND
}

MIND could not function without the help of individual psychiatrists and a basic sympathy and understanding on our part for what psychiatry is trying to achieve.

In summary MIND's aims are the improvement of knowledge about mental health and mental disorder; the encouragement and demonstration of good practice in prevention and treatment; raising the standards of existing services and encouraging new and improved forms of care and treatment; unholding the rights and meeting the needs of patients; mobilizing volunteers; research and the provision of information; providing advisory, counselling, advocacy and, to a limited extent, residential services; maintaining education and training programmes and raising funds both to keep going and to start more mental health projects.

We have a good track record in all these areas but, recognizing the near impossibility of covering the waterfront, we have from time to time picked particular themes to focus our energies and to measure our achievements. These have included the Home and Hospital campaign, which raised the level of accommodation provision for mental patients from 700 in 1976 to 1435 at the end of last year; a campaign for more and better rehabilitation services and employment opportunities; and the 'Alert' campaign on behalf of elderly mental patients. We also have some preliminary ideas for programmes concerned with prevention and day care.

This paper is based on a talk given at the Winter Quarterly Meeting of the College on 10 February 1981. The full text, plus other details of MIND's work are available from MIND, 22 Harley Street, London WIN 2ED.

\section{The mental hospital}

Our dissatisfaction with the mental hospital system is well known and by no means unique. The achievement of modern psychiatry is probably common-ground between us and has certainly been a contributory factor in the steady decline of the mental-illness hospital population. We cannot and do not believe that the large isolated mental hospitals can provide the best kind of therapeutic environment, and we think it regrettable that so little progress has been made towards achieving Enoch Powell's vision of 1961 . We recognize the futility of proposing immediate closures of all large mental hospitals now, but we firmly believe that there has to be a reasonably coherent process of strategic and operational planning. We were alarmed, prematurely, it now seems, by the NHS Royal Commission's expressions of undying faith in the vast majority of existing mental hospitals. At our Annual Conference last year on the 'Future of the Mental Hospitals' we tried to tease out a vision of the next decade. Again, regrettably, few psychiatrists were present. Dearly as many people love their old mental hospitals they are falling apart in every sense. It remains obvious that the function of these hospitals has drastically changed over the last decade, and that in many of them the patient population has declined to the point at which they are hardly viable. The closure or merger of hospitals and the provision of district based alternatives demands realistic consideration.

The mental hospitals continue to provide the focus of political attention and will dictate, for better or for worse, the strategy and measure of service provision. It would be obviously impossible to find alternatives and to plan and 